\title{
Poster: An Empirical Study of the Product Owner Role in Scrum
}

\author{
Julian M. Bass \\ University of Salford \\ j.bass@salford.ac.uk \\ Clodagh Nic Canna \\ Ocuco Ltd \\ clodagh.niccanna@ocuco.com
}

Sarah Beecham, Mohammad Abdur Razzak

Lero, the Irish Software Research Centre, Ireland

sarah.beecham,abdur.razzak@lero.ie

\author{
John Noll \\ University of East London \\ j.noll@uel.ac.uk
}

\begin{abstract}
The Product Owner (PO) is critical for translating business needs into a software implementation by gathering and prioritizing requirements, and assessing whether features have met the definition of "done." There is a paucity of detail about how POs achieve this daunting task in practice with potential negative consequences for project success.

In this research we employed a mixed-method approach comprising two case studies in which we interviewed and observed 55 practitioners across 9 large multi-national companies and an SME. Using a cross-case analysis we identified twelve distinct Product Owner activities.

From our empirical findings we created a Product Owner role taxonomy and found eight generic activities common to all teams, projects and companies regardless of project size.
\end{abstract}

\section{CCS CONCEPTS}

- Software and its engineering $\rightarrow$ Software creation and management; Software development process management; Collaboration in software development;

\section{KEYWORDS}

Agile software development, Scrum, inter-team coordination, product owner role, SME, Global Software Development

ACM Reference Format:

Julian M. Bass, Sarah Beecham, Mohammad Abdur Razzak, Clodagh Nic Canna, and John Noll. 2018. Poster: An Empirical Study of the Product Owner Role in Scrum. In ICSE '18 Companion: 40th International Conference on Software Engineering Companion, May 27-June 3, 2018, Gothenburg, Sweden. ACM, New York, NY, USA, 2 pages. https://doi.org/10.1145/3183440.3195066

\section{INTRODUCTION}

Agile methods offer an approach to delivering value to the customer, improving productivity and product quality in software development [3]. There are three roles in the Scrum

Permission to make digital or hard copies of part or all of this work for personal or classroom use is granted without fee provided that copies are not made or distributed for profit or commercial advantage and that copies bear this notice and the full citation on the first page Copyrights for third-party components of this work must be honored. For all other uses, contact the owner/author(s).

ICSE '18 Companion, May 27-June 3, 2018, Gothenburg, Sweden

() 2018 Copyright held by the owner/author(s).

ACM ISBN 978-1-4503-5663-3/18/05.

https://doi.org/10.1145/3183440.3195066 approach: Product Owner, Scrum Master, and development team member. The Product Owner establishes a product vision and then elicits and prioritises requirements.

The Product Owner role is said to be "a cornerstone of successfully applying agile product management in Scrum" [8]. Yet, few studies report precisely how POs perform their role. We have observed Product Owners performing a surprisingly wide range of tasks and activities. In this research we examine what Product Owners actually do, through an empirical study of 55 practitioners in 10 separate organizations.

\section{BACKGROUND}

The Product Owner is responsible for communication between the customer and development teams [5]. The Product Owner "plays a crucial part not only in bringing new products to life but also in managing the product lifecycle" [8].

In larger scale agile projects, Product Owners organise themselves into teams [7]. The concept of Product Owner teams (with shared responsibilities) sees technical and governance issues added to the Product Owner responsibilities, in order to coordinate cooperating agile teams [1].

In this study we now undertake a cross-case analysis of 10 companies, and specifically ask What activities do Product Owners perform?

\section{METHOD}

In order to address our research question, we undertook a three phased cross-case analysis of ten organisations, all performing Scrum.

The first phase (Case Study 1) comprised 46 face-to-face semi-structured interviews conducted with practitioners in 9 large-scale multi-national companies (see Table 1), between January 2010 and March 2014. The interviews employed an open-ended interview guide and were recorded and then transcribed. A Glaserian grounded theory approach was used, informed by open coding, memo writing and constant comparison and theoretical saturation [4].

Building on the first phase, we triangulated findings with Case Study 2, a participant-observation study focusing on a development team from a medium-sized Irish-based software company Ocuco Ltd., conducted between January, 2016 and March, 2017, and validated by members of Ocuco Ltd.'s development organization (see Table 2). 


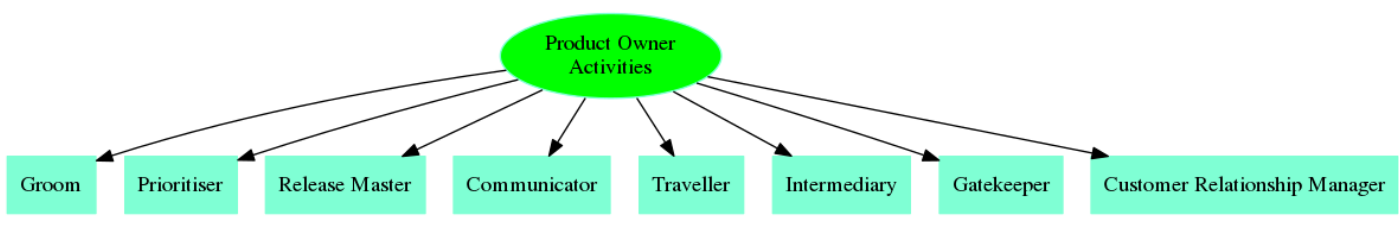

Figure 1: Product Owner activities from cross-case analysis

Table 1: Case Study 1 Demographic Information $(n=46)$

\begin{tabular}{|c|c|c|}
\hline Company & Company Sector & Participant Roles \\
\hline A, India & IT Service Provider & $\begin{array}{l}\text { Programme Manager, Senior Project Man- } \\
\text { ager, Team Member }\end{array}$ \\
\hline B, India & Internet & Engineering Manager, Product Manager \\
\hline C, India & $\begin{array}{l}\text { Software } \\
\text { Provider }\end{array}$ & Development Manager \\
\hline $\begin{array}{l}\text { D, India (offshore } \\
\text { provider to E) }\end{array}$ & $\begin{array}{l}\text { Software } \\
\text { Provider }\end{array}$ & $\begin{array}{l}\text { Project Manager, Product Owner, Scrum } \\
\text { Master (3), QA Lead, Team Member }\end{array}$ \\
\hline E, UK, England & Enterprise CRM & $\begin{array}{l}\text { Programme Manager, Project Manager, Di- } \\
\text { rector of Engineering }\end{array}$ \\
\hline F, India & Industrial Products & Scrum Master \\
\hline G, India & IT Service Provider & Engagement Manager \\
\hline $\mathrm{H}$, India & IT Service Provider & $\begin{array}{l}\text { Chief Technology Officer, Corporate Lead } \\
\text { Architect, General Manager Human Re- } \\
\text { sources, Delivery/Programme Manager (3), } \\
\text { Project/Senior Project Manager (3), Scrum } \\
\text { Master (2), Technical Analyst, Consultan- } \\
\text { t/Specialist (6), Team Member (9), Busi- } \\
\text { ness Analyst }\end{array}$ \\
\hline I, UK, Scotland & CRM & Chief Operating Officer \\
\hline
\end{tabular}

We observed approximately 200 of TeamA's Scrum ceremonies, and also conducted 9 semi-structured interviews of each member of TeamA, which were recorded and transcribed [2]. In phase three we employed a cross-case analysis [6] of our initial case study (Case Study 1) data and the new practices found in Case Study 2. We explored the results from all cases looking for similarities and differences.

\section{RESULTS}

The eight groups of Product Owner activities performed in all cases are shown in Fig. 1:

The Groom clarifies the details of product backlog items, and their respective acceptance criteria. The Prioritiser selects requirements that bring highest value or benefit. The Release Master manages and approves release plans. The Communicator transfers knowledge between onshore and offshore sites. The Traveller gathers an understanding of a client's needs by spending time onshore at customer sites. The Intermediary acts as an interface between senior roles, and the team, to disseminate domain knowledge. The Gatekeeper determines feature or story completeness for inclusion in a release. The Customer Relationship Manager provides technical support to customers, assists with site preparation and product installation, and does product training.

\section{CONCLUSIONS}

In this research we conducted two independent case studies and performed a cross-case analysis to discover Product
Table 2: Case Study 2 Demographic Information $(n=9)$

\begin{tabular}{llc}
\hline Ocuco Ltd. & Participant Role & \# participants \\
\hline \multirow{2}{*}{ Team A } & Product Owner & 2 \\
& Software Developer & 5 \\
& Quality Assurance & 1 \\
& Project Manager/Scrum Master & 1 \\
\hline
\end{tabular}

Owner activities from the perspective of 55 practitioners in 10 companies.

Our research shows that Product Owners perform a wide range of challenging activities which require experience and high-status in order to be able to exert influence over other project stakeholders.

As further work we will seek to publish more detailed descriptions of the Product Owner activities along with supporting evidence from our case studies and cross-case analysis.

\section{ACKNOWLEDGEMENTS}

We thank Ocuco Ltd., the companies and interviewees who participated in Case Study 1, the International Institute for IT, Bangalore, the UK Deputy High Commission, Bangalore. Accommodation and sustenance was provided by Company H. This work was supported, in part, by Science Foundation Ireland grants 10/CE/I1855 and 13/RC/2094.

\section{REFERENCES}

[1] J. M. Bass. 2015. How product owner teams scale agile methods to large distributed enterprises. Empirical Software Engineering 20,6 (2015), $1525-1557$.

[2] S. Beecham, J. Noll, and M. A. Razzak. 2017. Lean Global Project Interview Protocol. Available at http://bit.ly/2nPxaXH. (2017).

[3] T. Dybå and T. Dingsøyr. 2009. What Do We Know about Agile Software Development? IEEE Software 26, 5 (2009), 6-9. DOI: http://dx.doi.org/10.1109/MS.2009.145

[4] B. G. Glaser. 1998. Doing Grounded Theory: Issues and Discussions. Sociology Press, Mill Valley, USA.

[5] R. Hoda, J. Noble, and S. Marshall. 2011. The Impact of Inadequate Customer Involvement on Self-Organizing Agile Teams. Information and Software Technology 53, 5 (May 2011), 521-534. DOI: http://dx.doi.org/10.1016/j.infsof.2010.10.009

[6] M.B. Miles and A.M. Huberman. 1994. Qualitative data analysis: An expanded sourcebook. Sage Publications, Incorporated, Thousand Oaks, CA.

[7] M. Paasivaara, V. T. Heikkila, and C. Lassenius. 2012. Experiences in Scaling the Product Owner Role in Large-Scale Globally Distributed Scrum. In IEEE 7th International Conference on Global Software Engineering. IEEE, Rio Grande do Sul, Brazil, 174-178.

[8] R. Pichler. 2010. Agile Product Management with Scrum: Creating Products that Customers Love. Addison-Wesley Professional, Upper Saddle River, NJ. 